\title{
Maduromycosis of foot
}

\section{Mrinal Gupta}

\author{
Consultant Dermatologist, Treatwell Skin Centre, Jammu, India
}

Corresponding author: Dr Mrinal Gupta, E-mail: drmrinalgupta@yahoo.com

Maduromycosis is a progressive granulomatous infection of the skin and subcutaneous tissues which may involve muscle and bone. Mycetoma pedis (mycetoma of the foot), the most common form of mycetoma, is known widely as the Madura foot. The infection is endemic in Africa, India and South Americas and Madurella mycetomatis is the most prevalent cause of mycotic mycetoma worldwide. The characteristic clinical presentation includes a triad of tumor like swelling, draining sinuses, and macroscopic grains [1]. Infection usually follows a traumatic inoculation of the pathogen into subcutaneous tissue via contaminated mechanical vectors. This infection can spread and involve fascia, muscle, bone and regional lymph nodes [2]. Mycetoma requires long-term treatment, consisting of a combination of surgical procedures and prolonged medical therapy. In the absence of a correct diagnosis and appropriate treatment, mycetoma can lead to significant morbidity due to bone destruction and deformities [3].

A 45 year old male presented to us with 5 years history of gradually progressive swelling and painful nodular lesions over the plantar and lateral aspect of his right foot. The lesions were a single nodule to begin with, but over the time, they had increased in size and number to their present size, and there was history of intermittent purulent discharge and crusting over these nodules. He did not recall any predisposing injury and did not suffer from systemic symptoms. On physical examination, the patient had a large swelling in the dorsum of his right foot with multiple crusted nodules and sinuses draining purulent fluid (Fig. la and b). There was no lymphadenopathy. Other systems were normal.

A biopsy of the lesions was done which revealed large amount of black grains, with a reactive

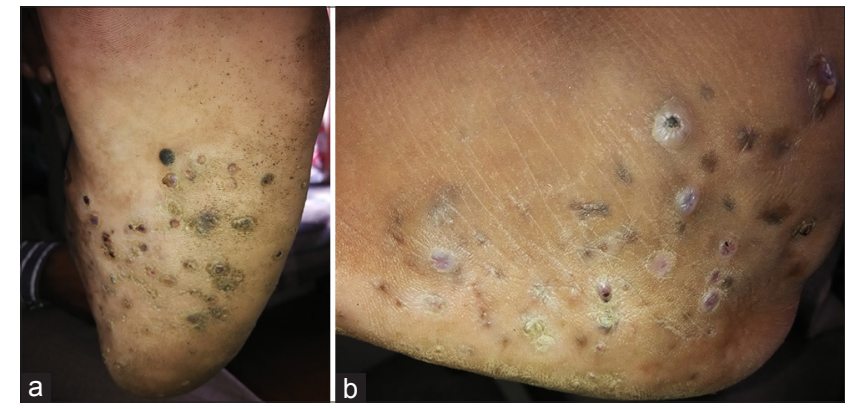

Figure 1: $(a$ and $b)$ Multiple crusted nodules and sinuses present over the foot.

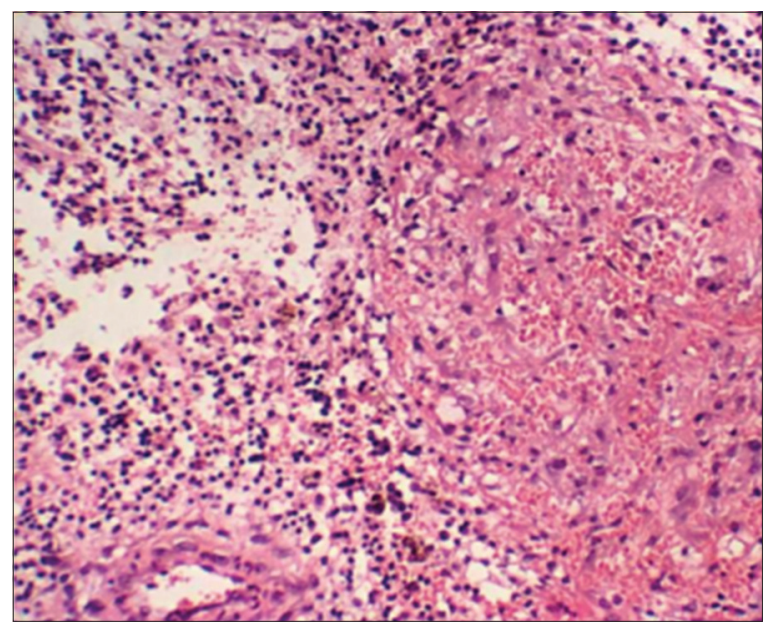

Figure 2: Histopathology showing dense inflammatory infiltrate with few dark grains.

inflammatory process surrounding the lesion (Fig. 2), which confirmed the diagnosis of Maduromycosis. The patient was treated with Itraconazole for 6 months which showed mild improvement in symptoms.

\section{REFERENCES}

1. Venkatswami S, Sankarasubramanian A, Subramanyam S. The madura foot: looking deep. Int J Low Extrem Wounds. 2012;11:31-42. 
www.odermatol.com

2. Ahmed AO, van Leeuwen W, Fahal A, van de Sande W, Verbrugh H, van Belkum A. Mycetoma caused by Madurella mycetomatis: a neglected infectious burden. Lancet Infect Dis. 2004;4:566-74.

3. Abd Bagi ME, Fahal AH, Sheik HE, Abdul Wahab O, Taifoor MK, Osmanr EM. Pathological fractures in mycetoma. Trans R Soc Trop Med Hyg. 2003;97:582-4.
Copyright by Mrinal Gupta. This is an open access article distributed under the terms of the Creative Commons Attribution License, which permits unrestricted use, distribution, and reproduction in any medium, provided the original author and source are credited.

Source of Support: Nil, Conflict of Interest: None declared. 